The following is the prepublication text of

Andrews, P. (2016). Understanding the cultural construction of school mathematics. In B. Larvor (Ed.), Mathematical Cultures: The London meetings 2012-2014 (pp. 9-23). Basel: Birkhäuser.

http://dx.doi.org/10.1007/978-3-319-28582-5_2

\title{
Understanding the cultural construction of school mathematics
}

Paul Andrews, Stockholm University

\section{Introduction}

For more than twenty years I have been observing, video-recording and analysing mathematics teaching in various European countries. In addition, due to the generosity of my graduate students and other colleagues, I have acquired video recordings of mathematics lessons from several other European countries. My interpretation of all this material has led me to two conclusions. The first, as found throughout the literature (Schmidt et al., 1996; Hiebert et al., 2003), is that mathematics teachers tend to behave in ways that align them more closely with their compatriots than with teachers elsewhere. The second, which may in part explain the first, is that the cultures in which teachers operate have as much, if not more, influence on student achievement as the ways in which mathematics is taught. For example, successive iterations of the programme of international student assessment (PISA) (OECD, 2001, 2004, 2007, 2010a, 2013) have highlighted Finnish students' linguistic and mathematical competence. However, recent analyses indicate that such successes may be due more to matters cultural than didactical (Andrews, 2011, 2013; Andrews et al., 2014). I return later to the issue of Finland, which is particularly significant in light of continual media and other attention paid that country. But first it as important to explain what this chapter will, and will not, attempt to achieve. The principal aim is to show how culture, the meaning of which will be discussed below, underpins all aspects of school mathematics, whether it be the curriculum specified by the system, the development of the textbooks that teachers may or may not be compelled to use, the ways teachers teach, the classroom interactions privileged by the system or the beliefs, attitudes and aspirations of teachers, students and parents. To do this, however, requires some understanding of the nature of culture and its educational manifestation.

\section{The nature of culture}

Of course, such ambitions may be more difficult to achieve than might be expected as culture is not only "one of the two or three most complicated words in the English language" (Williams, 1976, p. 76) but also "a profoundly congested concept" (Lewis, 2007, p.867). In part, this is due to the fact that;

Culture is ordinary: that is the first fact. Every human society has its own shape, its own purposes, its own meanings. Every human society expresses these, in institutions, and... learning. The making of a society is the finding of common meanings and directions, and its growth is an active debate and amendment, under pressures of experience, contact, and discovery, writing themselves into the land. The growing society is there, yet it is also made and remade in every individual mind. The making of a mind is, first, the slow learning of shapes, purposes, and meanings, so that work, observation and communication are possible. Then, second, but equal in importance, is the testing of these in experience, the making of new observations, comparisons, and meanings (Williams, 1958, p. 75).

From Williams' definition can be inferred several key characteristics; culture is a group construction based on common experiences. It is not fixed but changeable. An individual's cultural affiliation is the result of an implicit negotiative process, indicating that the influence of culture as a guiding force in the life of individuals is largely hidden. Culture, in this sense, can be construed as a way of life (Lewis, 2007; Williams, 1976).

This way of life interpretation implies a consensus that culture comprises a collective psychological conditioning (Triandis \& Suh, 2002). It embodies the "implicitly or explicitly shared abstract ideas about what is good, right, and desirable in a society" (Schwartz, 1999, p. 25), and includes those beliefs, artefacts, practices and institutions that history has shown to be effective for the maintenance of a society and its future generations (Fiske, 2002; Hofstede, 1980; Triandis \& Suh, 2002). Cultures are social, historical and 
behavioural constructions (Fiske, 2002) that reflect the "collective mental programming" of their people (Hofstede, 1980, p. 43). Through the transmission of their embedded values, beliefs, knowledge and skills, they ensure replication. Hence, people's psychological processes "are likely to be configured in different ways across different socio-cultural groups" (Erez \& Gati, 2004, p.568). Summarising the above, Triandis (2007, p.64) writes that culture comprises three main characteristics; it "emerges in adaptive interactions between humans and environments", it comprises shared elements and "is transmitted across time periods and generations" and, therefore, largely stable (Soares et al., 2007). In the following I consider several educationally-salient features of culture and show, in various ways, how they impact on students' opportunities to learn. In so doing, I acknowledge that "schools can rise no higher than the communities that support them" (Boyer 1983, p.6) and, in trying to understand the processes of education, that "the things outside the schools matter even more than the things inside the schools, and govern and interpret the things inside" (Sadler (1900) in Bereday, 1964 p.310).

\section{Modelling culture}

A number of researchers, typically aligned with an anthropological tradition (Soares et al., 2007) have attempted to identify those dimensions that distinguish one culture from another, and it is to them that I turn first. Hofstede's well known study initially identified four dimensions of culture. The first, power distance, concerns the extent to which followers accept being led. "A society's power distance level is bred in its families through the extent to which its children are socialized toward obedience or toward initiative" (Hofstede \& McCrae, 2004, p. 62). The second, uncertainty avoidance, relates to the extent to which "a culture programs its members to feel either uncomfortable or comfortable in unstructured situations". The third is individualism, or the "degree to which individuals are integrated into groups". Lastly there are masculine as opposed to feminine cultures. Masculine cultures "strive for maximal distinction between what men are expected to do and what women are expected to do". From the perspective of education, Hofstede (1986) has used these dimensions to predict culturally determined differences in the social positions of teachers and students, participants' cognitive and affective expectations, and patterns of participant interactions.

Others, have proposed different but related models of culture. For example, Triandis (2001) offered eleven dimensions and Schwartz (1999) seven. Like Hofstede's dimensions, both categorisations help us to understand the role of culture in framing humans' decision making in general and the processes of education in particular. Significantly, Schwartz focused on elementary teachers' education-related values in more than 40 countries, arguing that teachers "play an explicit role in value socialisation", are likely to be "key carriers of culture, and... reflect the mid-range of prevailing value priorities in most societies" (Schwartz, 1999, p. 34). He found, for example, that conservative cultures which emphasise the "maintenance of the status quo... or the traditional order" would structure educational opportunities very differently from an autonomous culture in which an individual finds "meaning in his or her own uniqueness... and is encouraged to do so" (Schwartz, 1999, p. 34). All such models help us to understand that forces, possibly beyond participants' consciousness, act to shape what happens in classrooms. They "determine what is to be taught, to whom it is taught, how it is to be taught and where it is taught" (Andrews, 2010, p.5).

\section{Culture and curricula}

The curriculum, according to the second international mathematics study, comprises intended, implemented and attained forms. However, what is frequently missing from such discussions is the extent to which cultural forces shape curricula developments in different countries. In this respect a curriculum can be construed as "both material artefact", the sphere of the cultural anthropologist, and "symbolic system", the sphere of the cultural sociologist. That is, the curriculum reflects both a way of life, including the "shared values and meanings common to members of the group" and the practices by which meaning is constructed and shared within the group (Mason, 2007, p.172). In much the same way as with culture above, various analysts have modelled curricula. For example, Holmes and McLean (1989) have presented four curriculum models; essentialism, derived from the English public ${ }^{1}$ school, encyclopaedism, linked to post-revolutionary France and its Enlightenment principles, polytechnicalism, tied to Soviet expectations of vocationalism underpinned by an encyclopaedic model of knowledge, and pragmatism, derived from the United States and

1

The adjective public in this context is misleading; an English public school is an elite independent school. Such schools sustain the higher ranks of the civil service and the judiciary, half of all students at Cambridge and Oxford universities, and a disproportionately high number of members of parliament. 
a need for the knowledge and skills necessary for tackling the real world problems of a liberal economy. In similar vein, Kamens et al. (1996) categorise upper secondary curricula in four ways; classical curricula address the maintenance of the natural social order through the training of a political and social elite, comprehensive curricula, reflecting egalitarian principles, aim to produce competent and productive citizens, mathematics and science curricula reflect economic needs for a technologically competent work-force, and arts, humanities, and modern languages curricula, reflecting a modernisation of the classical European curriculum, focus on the maintenance of an elite high culture. Finally, it has been asserted that few of the world's curricula are not adaptations of one of six core curricula - the Prussian, Russian, French, English, Japanese and United States (Cummings, 1999).

Of course, such characterisations are crude and may not reflect the particularities of individual systems. For example, social scientists have tended to "conceptualize individualism as the opposite of collectivism, especially when contrasting European American and East Asian cultural frames (Oyserman et al., 2002, p. 3). However, such conceptions are, in some ways, confounded by analyses of the European context. Weber (1930) observed that Protestant cultures, focused on the promotion of self-reliance, tended towards the individualist while Catholic, due to emphases on the maintenance of established hierarchical relationships, tended to the collectivist. Admittedly, increasing mobility as a result of the European Union and other post colonial immigration, may have compromised the obvious relevance of such characterisations, but few national curricula do not attempt to instil in their students a sense of the national character, if only in the ways that literature is managed. In other words, while models such as those presented above highlight how curricula may vary substantially in both principle and manifestation, few modern curricula are so tightly located in a single cultural context that they remain untouched by developments elsewhere (Kamens et al., 1996), particularly in the light of recent international tests of student achievement, especially TIMSS and PISA. Indeed, such tests are, essentially, underpinned by assumptions that mathematics is in the vanguard of curricular convergence; after all, an equation is an equation irrespective of where it is found, isn't it? In the following, therefore, I show, with reference to various European educational systems, how curricular mathematics and its classroom presentation varies according to culturally established norms.

\section{Culture and mathematics curricula}

In the following, using them as a placeholder for mathematics, I summarise four European system's curricular perspectives on linear equations before discussing them in relation to the various characteristics of culture. In so doing, I try to show how curricula are constructed. Choice, in respect of the countries under scrutiny, was constrained by the availability of curricula in English, while the topic was determined by other work on which I am engaged. Each is presented alphabetically by country, with details referring only to content related explicitly to the formulation and solution of linear equations. Thus, references to solving simultaneous linear equations, for example, have been omitted in the interests of narrative simplicity.

The English national curriculum ${ }^{2}$ for students in the age range 11-14 asserts that pupils, under the umbrella of developing fluency, should, inter alia, "solve equations". They should "move freely between different numerical, algebraic, graphical and diagrammatic representations [for example,... equations and graphs]". More particularly, pupils should be taught to "understand and use the concepts and vocabulary of... equations", "use algebraic methods to solve linear equations in one variable (including all forms that require rearrangement)"

The Finnish national curriculum ${ }^{3}$ for grades 6-9 asserts that students, by the end of grade 8, "will know how to... solve a first degree equation".

The Flemish mathematics curriculum ${ }^{4}$, expects students in the first grade of secondary education to "solve equations of the first grade with one unknown and simple problems which can be converted to such an equations". During the second grade they will "solve equations of the first and second degree in one unknown and problems which can be converted into such equations".

The Hungarian curriculum ${ }^{5}$ for grades 5-8 (upper primary) writes that in year 5 students should "solve simple

\section{$2 \quad$ See}

https://www.gov.uk/government/uploads/system/uploads/attachment_data/file/239058/SECONDARY_national_curricul um_-_Mathematics.pdf

3 See http://www.oph.fi/english/publications/2009/national_core_curricula

4 See http://www.ond.vlaanderen.be/dvo/english/

5 See http://www.okm.gov.hu/letolt/nemzet/kerettanterv36.doc 
equations of the first degree by deduction, breaking down, checking by substitution along with simple problems expressed verbally". In year 6 they should "solve simple equations of the first degree and one variable with freely selected method". By year 7 they should "solve simple equations of the first degree by deduction and the balance principle. Interpret texts and solve verbally expressed problems. Solve equations of the first degree and one variable by the graphical method". Lastly, by year 8 students should "solve deductively equations of the first degree in relation to the base set and solution set. Analyse texts and translate them into the language of mathematics. Solve verbally expressed mathematical problems"

From these examples can be discerned different perspectives on a core topic of the lower secondary curriculum. Unlike the Flemish and Hungarian curricula, neither the English nor the Finnish documents offer year-on-year progression, with both specifying outcomes to be achieved by the end of a particular phase. Indeed, it is difficult to imagine a less detailed specification than the Finnish. Neither curriculum specifies methods, although the English alludes to a recommended algebraic rearrangement method. Neither document makes explicit mention of problem solving or word problems and the derivation of equations from text. The Flemish document, which also says nothing about approaches, appears superficially more tightly specified although the shift from one year to the next is vague. However, there is a clear sense that students are expected to derive and solve equations from, by implication, word problems. Finally, the Hungarian curriculum offers a tightly specified progression over a four year period with methods and problem solving, including word problems, increasingly specified and exploited.

So, how do the various cultural norms play out in the curricular presentation of mathematics? The two countries with the loosest curricula expectations, England and Finland, reflect horizontal cultures (Triandis, 2001) where power distance and uncertainty avoidance are low (Hofstede, 1980). In countries with low power distance, "people at various power levels feel... prepared to trust people" (Hofstede, 1980, p.46). In other words, curriculum authorities see no need to over-specify, say, teaching approaches because teachers are trusted to manage their responsibilities appropriately. Indeed, Finnish teachers operate within a culture of trust (Välijärvi, 2004) that extends from the top to the bottom (Sahlberg, 2007); they enjoy high public esteem (Simola, 2005) and are viewed as professionals who know what is best for their students (Aho et al., 2006). In similar vein, loosely structured curricula found in countries with low uncertainty avoidance reflect societal norms in which not only is "the uncertainty inherent in life... more easily accepted and each day... taken as it comes" but also a culture in which dissent and deviation are tolerated and people are willing to take risks (Hofstede, 1980, p. 47). The Flemish situation is different, although it is important for the reader to understand that Hofstede's studies focused on Belgium as a whole and not just Flanders. Relatively high levels of power distance and uncertainty avoidance may help explain why the Flemish authorities produced a more tightly structured curriculum than the English or the Finns. Further, the very tightly specified Hungarian curriculum would be a product of a culture in which power distance and uncertainty avoidance are higher than the other three countries under scrutiny. In other words, there appears to be a relationship between the degree to which a curriculum is specified and the levels of both power distance and uncertainty avoidance - the lower the cultural dimensions the less specified the curricula. Alternatively, the loosely structured curricula of the English and the Finns may be artefacts of autonomous (Schwartz, 1999) protestant (Weber, 1930) cultures, while the more structured curricula of the Flemish, and particularly the Hungarians, could be construed as reflecting more conservative (Schwartz, 1999) Catholic (Weber, 1930) cultures. In short, it is not inconceivable that differences in the presentation of mathematics curricula are consequences of significant differences in the underlying structures of the cultures themselves. In the following I consider how such difference play out in mathematics classrooms.

\section{Culture and mathematics teaching}

If, as suggested above, teachers are proxies for a system's values then it would surprising if teachers' actions were not culturally determined manifestations of those values. In this respect, it is widely thought that mathematics teaching in the West differs from that in the East. For example, a number of researchers have emphasised the influence of Socratic and Confucian philosophies on the culturally West and culturally Chinese educational traditions (Leung, 2001; Tweed \& Lehman, 2002; Watkins, 2000). Indeed, in respect of mathematics, Leung (2001) proposed six dichotomies that distinguish between East Asian and Western mathematics classrooms; product (content) versus process, rote learning versus meaningful learning, studying hard versus pleasurable learning, extrinsic versus intrinsic motivations, whole class teaching versus individualised learning, teacher competence in relation to the subject matter versus pedagogy debate. However, such distinctions are not only crude and, at times, inaccurate (Clarke, 2006) but frequently slide into unconscious stereotyping or even racism (Mason, 2007). In the following, mindful of such problems, I 
focus on European systems and the more subtle ways in which cultures influence educational practices in general and mathematics teaching in particular. For example, at the general level, Osborn (2004) has shown how societal privileging of the individual, the community and the nation - emphases explicable by reference to the various cultural models discussed above - underpin educational expectations and practices in, respectively, England, Denmark and France. With respect to the particulars of mathematics, the antiscientific traditions of the English curriculum and the rational encyclopaedic traditions of the French curriculum (Holmes and McLean, 1989, Cummings, 1999) may explain findings that English mathematics teachers work to reduce the complexity of mathematics for their students, while French teachers work towards an "induction into that complexity" (Jennings and Dunne, 1996, p.51). In similar vein, Kaiser (2002) found substantial differences between the traditions of English and German mathematics teaching explicable by the socio-historical underpinnings of the two systems. For example, in German classrooms "theoretical mathematical considerations are of great importance" while English mathematics teaching privileges a "pragmatic understanding of theory" (p. 249). German mathematics is defined by the structure of the subject with large thematic fields taught independently of each other, while in England a spiral curriculum allows topics to be introduced, revisited later and taught independently of any obvious sense of structure. In Germany new topics or methods are introduced by means of class discussions and often illustrated by realworld examples, while in England they have a low importance and are often given "as information or in the style of a recipe" (p. 250). German lessons are progressed by high expectations of students' correct and confident execution of algorithms, with clear expectations that each is undertaken in well-defined and predetermined ways. In English lessons "rules and standard algorithms (are) of minor importance" (p. 252), with priority given to students' own solutions. German teachers place great importance on precise mathematical language at all levels of discourse, while English teachers view such matters as of minor importance.

The content and structure of mathematics text books, too, show evidence of being culturally determined. Haggarty and Pepin (2002) analysed commonly used English, French and German textbooks and found evidence supportive of the differences discussed in the previous paragraph. For example, French texts, which were cognitively challenging, incorporated extensive explanatory text and technical vocabulary sufficient for students to "do the questions ... without additional support" (p. 576). German texts, incorporating detailed explanatory text and much technical vocabulary, attempted to establish links "between everyday situations and what pupils are to learn" (p. 578), although typically questions required only low-level applications of the skills being practised. English texts were less dense and contained fewer examples. There was little emphasis on technical vocabulary and no explanatory text. Exercises were low level with little scope for extension (p. 582). Finally, with respect to textbooks, cultures differ in their production and deployment. For example, all Greek teachers are mandated to use centrally produced textbooks (Hatzinikita et al., 2008), whereas the supply of textbooks in England is unregulated. Such matters can also be explained by cultural analyses. Greece, despite being an Orthodox community, would be construed as collectively Catholic under a Weberian analysis, an argument supported by its having one of the largest power distances of all European countries and the largest uncertainty avoidance in the world (Hofstede, 1986). Such cultural characteristics differ greatly from the English described above.

To further illustrate the diversity of European mathematics didactics traditions, I return to the topic of linear equations and a qualitative analysis of a sequence of five lessons taught in each of Finland, Flanders and Hungary (Andrews and Sayers, 2012). They found, at the level of didactical structure, that each sequence passed through four phases, which they described as definition, activation, exposition and consolidation. The definition phase, always a whole-class activity, introduced students to the notion of an equation and, either implicitly or explicitly, presented a definition. The activation phase, predominately whole-class, involved students solving equations with the unknown on one side of the equals sign. Such equations allow for intuitive approaches, typically based on inverse operations. The exposition phase, which was always whole class activity focused on solving an equation with the unknown on both sides of the equal sign, exposed the inadequacies of intuitive approaches and warranted the introduction of the balance as a didactic tool. Finally, the consolidation phase, which incorporated both whole-class and individual working, enabled students to practice and exploit their newly acquired skills. However, when the analyses went beyond such straightforward similarities, substantial differences were observed. The Hungarian teacher, focused much of her time on encouraging her students to construct equations from word problems. These equations, which were alternated with equations derived from problems set in a world of mathematics, were always cognitively challenging but, after periods of individual work, collectively solved in ways that privileged the students' voice focused on a collectively agreed solution. The Flemish teacher, used a word problem to 
introduce the topic but then spent much of her time working on cognitively challenging problems located in a world of mathematics. However, the solutions to such problems were managed in ways that minimised opportunities for students to engage in individual problem solving, with her always being the final arbiter of what constituted an appropriate solution. Finally, the Finnish teacher, exploited only problems set in a world of mathematics. These were always routine, never cognitively challenging, and always solved in ways that minimised or ignored the student voice. Such teacher behaviours, which resonated closely with the available literature on each teacher's country's didactical practices, further highlight how teachers are conditioned to act in particular ways by the culture in which they live and work (Andrews \& Sayers, 2013) and lead us, as promised earlier, back to Finland.

Finland, a country much admired for its repeated successes on the five iterations of PISA, has attracted many thousands of foreign envoys keen to uncover curriculum-related insights (Laukkanen 2008, 2013). Indeed, such activity has been encouraged by the OECD's extraordinary assertion that "bringing all countries up to the average performance of Finland, OECD's best performing education system in PISA, would result in gains in the order of USD 260 trillion" over the "lifetime of the generation born in 2010" (OECD 2010b, p.6). However, as I show below, the assumption that emulating Finnish practice will raise achievement elsewhere may be naïve. For example, and typically downplayed by the Finnish authorities, has been Finnish students' modest achievement on the two TIMSS in which Finland has participated. Indeed, in both 1999 and 2011, Finnish students' algebraic and geometric competence barely reached the level of the international mean (Mullis et al. 2000, 2012). This disparity between high PISA and, in real terms, low TIMSS has not only prompted Finnish mathematicians to suggest that the mathematical knowledge and skills necessary for further study of the subject have been sacrificed in the continuing pursuit of PISA success (Astala et al. 2006; Martio 2009; Tarvainen and Kivelä 2006) but leads one to ask, what is happening in Finnish classrooms that might explain success on one form of test and failure on the other?

Early analyses of Finnish classrooms have been particularly critical. Research undertaken more than a quarter of a century ago found teaching practices that had not only changed little in fifty years but created an intelligence and emotional wasteland (Carlgren et al., 2006). More recently, but preceding Finland's PISA successes, Norris et al. (1996, p.29) found "rows and rows of children all doing the same thing in the same way whether it be art, mathematics or geography", adding that they had "moved from school to school and seen almost identical lessons, you could have swapped the teachers over and the children would never have noticed the difference". During the PISA years, Andrews and his colleagues, in an attempt to understand the relationship between Finnish mathematics-related didactics and PISA success undertook three, differently framed qualitative analyses of video sequences of Finnish mathematics lessons. The first, based on Kilpatrick et al.'s (2001) five strands of mathematical proficiency, found no evidence of Finnish teachers encouraging students to acquire the higher order skills conducive to problem solving; the primary objective seemed to be procedural competence located on limited conceptual knowledge (Andrews 2013). The second, exploiting PISA's own assessment framework, found no evidence of students being encouraged to acquire the higher level competences they demonstrated in repeated PISA assessments (Andrews et al. 2014). The third, based on a constant comparison analysis in which data were not subjected to predetermined frameworks, found a didactical tradition in which teachers posed many closed questions but never evaluated or sort clarification relating to a student's response. Thus, correct, partially correct, incomplete or incorrect student responses received the same, non-commital teacher feedback. This implicit tradition, where students infer meaning from any given set of teacher-student interactions, dominated all analysed lessons (Andrews, 2011). Thus, while Finnish didactical traditions may be unable explain Finnish students' continuing PISA successes, they may help us to understand their repeated TIMSS failures, which leads naturally to the final question, what does explain Finnish PISA success? This final question takes us to another key relationship between culture and education.

A number of factors, assumed contributory to students' continuing PISA successes, have been proposed by the Finns themselves. These concern the quality of the comprehensive school system and its compulsory common curriculum (Aho et al., 2006), exceptional special educational needs arrangements (Hausstätter \& Takala, 2011; Kivirauma \& Ruoho 2007) and the high quality of teacher education (Antikainen, 2006; Laukkanen, 2008; Niemi \& Jakku-Sihvonen, 2006; Tuovinen, 2008; Välijärvi, 2004). However, such studies have, as is increasingly typical in Finland, failed to acknowledge the problem of TIMSS. A few, less triumphal, authors have suggested that Finnish PISA success may be a consequence of other factors, largely independent of school. Firstly, cultural homogeneity (Välijärvi et al, 2002) has made it "comparatively easy in Finland to reach mutual understanding on national education policy and the means for developing the education system". (Välijärvi et al., 2002, p. 45). Moreover, Finnish cultural homogeneity, born of frequently 
violent struggles between the Finnish people and oppressors from both east and west, has created a collective mindset not dissimilar to those of Japan and Korea (Simola, 2005). In particular, "there is something archaic, something authoritarian, possibly even something eastern, in the Finnish culture and mentality" (Simola, 2005, p. 458). Secondly, this sense of the authoritarian collective finds resonance in the tradition that participation in Finnish cultural life has, since post-reformation times, been dependent on a public demonstration of reading competence, which was a precondition not only for receiving the sacraments but also for contracting a Christian marriage (Linnakylä, 2002). Consequently, as Mason (2007, p. 167) notes, "given what we now know of the relationship between levels of parental education and the educational achievements of their children, it does not take a social Darwinian perspective ...to realize the effect over centuries of a cultural practice that has meant that almost all children in Finland have been raised in families where both parents are literate". Consequently, the Finns have acquired a collective appreciation for education in general and Finnish literature in particular (Halinen \& Järvinen 2008), to the extent that the Finnish library network is among the world's densest, with Finns borrowing more books than anyone else (Sahlberg, 2007). Such traditions, based on the creations of one of the world's most literary cultures, explain why Finnish students achieve well on PISA and not on TIMSS; they read with competence, they can interpret text and extract relevant material before undertaking the simple mathematics expected of a typical PISA item. Mathematically, TIMSS asks so much more of a student, and, in this respect, Finnish students are no more competent than any other students in the West. In short, the available evidence shows that culture may play a more significant role than pedagogy in determining the educational achievements of country, a finding that should be of great concern to anyone with an interest in improving both mathematics teaching and student achievement.

\section{Conclusions}

In this chapter I have tried to demonstrate the extent to which teaching in general and mathematics teaching in particular are culturally determined activities. There is a temptation, particularly among academic mathematicians and policy makers, to assume that school mathematics is the same wherever it is experienced. This is simply not true. Research shows consistently that teachers' practices reflect "culturally determined patterns of belief and behaviour, frequently beneath articulation, that distinguish one set of teachers from their culturally different colleagues" (Andrews and Sayers, 2013, p.133). Wherever they are located, lessons "have a routineness about them that ensures a degree of consistency and predictability" (Kawanaka et al, 1999, p. 91). This sense of routine predictability has been variously described as the traditions of classroom mathematics (Cobb et al., 1992), the characteristic pedagogical flow of a lesson (Schmidt et al., 1996), the cultural script (Stigler and Hiebert, 1999) and the lesson signature (Hiebert et al., 2003). Such descriptions allude to repeatedly enacted pedagogical strategies typical of a country's lesson (Cogan \& Schmidt 1999). In this manner culture "shape the classroom processes and teaching practices within countries, as well as how students, parents and teachers perceive them" (Knipping, 2003, p.282). Indeed, so significant is this hidden role of culture that many of the processes of teaching are so "deep in the background of the schooling process ... so taken-for-granted... as to be beneath mention" (Hufton \& Elliott, 2000, p.117). That said, I hope the above pages have highlighted the complex relationship between culture, however it is defined, and the processes and practices of education in general and mathematics education in particular.

\section{References}

Aho, E., Pitkänen, K., \& Sahlberg, P. (2006). Policy development and reform principles of basic and secondary education in Finland since 1968. Washington: The World Bank.

Andrews, P. (2010). The importance of acknowledging the cultural dimension in mathematics teaching and learning research. Acta Didactica Napocensia, 3(2), 3-16.

Andrews, P. (2011). Finnish mathematics teaching: A case of uniquely implicit didactics. In T. Dooley, D. Corcoran \& M. Ryan (Eds.), Proceedings of the Fourth Conference on Research in Mathematics Education (MEI 4): Mathematics Teaching Matters (pp. 3-18). Dublin: St Patrick's College.

Andrews, P. (2013). Finnish mathematics teaching from a reform perspective: A video-based case study analysis. Comparative Education Review, 57(2), 189-211.

Andrews, P., \& Sayers, J. (2012). Teaching linear equations: Case studies from Finland, Flanders and Hungary. The Journal of Mathematical Behavior, 31(4), 476-488.

Andrews, P., \& Sayers, J. (2013). Comparative studies of mathematics teaching: does the means of analysis 
determine the outcome? ZDM: The International Journal on Mathematics Education, 45(1), 133-144.

Andrews, P., Ryve, A., Hemmi, K., \& Sayers, J. (2014). PISA, TIMSS and Finnish mathematics teaching: an enigma in search of an explanation. Educational Studies in Mathematics, 87(1), 7-26.

Antikainen, A. (2006). In search of the Nordic model in education. Scandinavian Journal of Educational Research, 50(3), 229-243.

Astala, K., Kivelä, S., Koskela, P., Martio, O., Näätänen, M., \& Tarvainen, K. (2006). The PISA survey tells only a partial truth of Finnish children's mathematical skills. Matilde, 29, 9.

Bereday, G. (1964). Sir Michael Sadler's 'Study of Foreign Systems of Education'. Comparative Education Review, 7(3), 307-314.

Boyer, E. L. (1983). High School: A report on secondary education in America. New York: Harper \& Row.

Carlgren, I., Klette, K., Mýrdal, S., Schnack, K., \& Simola, H. (2006). Changes in Nordic teaching practices: From individualised teaching to the teaching of individuals. Scandinavian Journal of Educational Research, 50(3), 301-326.

Clarke, D. (2006). Using international research to contest prevalent oppositional dichotomies. ZDM, 38(5), 376-387.

Cobb, P., Wood, T., Yackel, E., and McNeal, B. (1992) Characteristics of classroom mathematics traditions: An interactional analysis. American Educational Research Journal, 29 (3), 573-604.

Cogan, L., and Schmidt, W. (1999) An examination of instructional practices in six countries. In G. Kaiser, E. Luna and I. Huntley (Eds.), International comparisons in mathematics education (pp. 68-85). London: Falmer.

Cummings, W. (1999) The InstitutionS of education: Compare, Compare, Compare! Comparative Education Review, 43(4), 413-437.

Erez, M., \& Gati, E. (2004). A dynamic, multi-level model of culture: From the micro level of the individual to the macro level of a global culture. Applied Psychology: An International Review, 53(4), 583-598.

Fiske, A. P. (2002). Using individualism and collectivism to compare cultures - A critique of the validity and measurement of the constructs: Comment on Oyserman et al. (2002). Psychological Bulletin, 128(1), 78-88.

Haggarty, L., and Pepin, B. (2002) An investigation of mathematics textbooks and their use in English, French and German classrooms: who gets an opportunity to learn what? British Educational Research Journal, 28(4), 567-590.

Halinen, I., \& Järvinen, R. (2008). Towards inclusive education: the case of Finland. Prospects, 38(1), 77-97.

Hausstätter, R., \& Takala, M. (2011). Can special education make a difference? Exploring the differences of special educational systems between Finland and Norway in relation to the PISA results. Scandinavian Journal of Disability Research, 13(4), 271-281.

Hiebert, J., Gallimore, R., Garnier, H., Bogard Givvin, K., Hollingsworth, H., Jacobs, J., et al. (2003) Teaching mathematics in seven countries: results from the TIMSS 1999 video study. Washington: National Center for Educational Statistics.

Hofstede, G. (1980) Motivation, leadership and organization: Do American theories apply abroad? Organizational Dynamics, (Summer 1980), 42-63.

Hofstede, G. (1986) Cultural differences in teaching and learning. International Journal of Intercultural Relations, 10(3), 301-320.

Hofstede, G., and McCrae, R. (2004) Personality and culture revisited: Linking traits and dimensions of culture. Cross-Cultural Research, 38(1), 52-88.

Holmes, B., and McLean, M. (1989) The Curriculum: a comparative perspective. London: Unwin Hyman.

Hufton, N., and Elliott, J. (2000) Motivation to learn: the pedagogical nexus in the Russian school: some implications for transnational research and policy borrowing. Educational Studies, 26(1), 115-136.

Jennings, S., and Dunne, R. (1996) A critical appraisal of the National Curriculum by comparison with the 
French experience. Teaching Mathematics and its Applications, 15(2), 49-55.

Kaiser, G. (2002). Educational philosophies and their influence on mathematics education - an ethnographic study in English and German mathematics classrooms. ZDM, 34(6), 241-257.

Kamens, D., Meyer, J., \& Aaron, B. (1996). Worldwide patterns in academic secondary education curricula. Comparative Education Review, 40(2), 116-138.

Kawanaka, T., Stigler, J., and Hiebert, J. (1999) Studying mathematics classrooms in Germany, Japan and the United States: lessons from the TIMSS videotape study. In G. Kaiser, E. Luna and I. Huntley (Eds.), International comparisons in mathematics education (pp. 86-103). London: Falmer.

Kilpatrick, J., Swafford, J., \& Findell, B. (Eds.). (2001). Adding it up: helping children learn mathematics. Washington, DC: The National Academies Press.

Kivirauma, J., \& Ruoho, K. (2007). Excellence through special education? Lessons from the Finnish school reform. International Review of Education, 53(3), 283-302.

Knipping, C. (2003) Learning from comparing: A review and reflection on qualitative oriented comparisons of teaching and learning mathematics in different countries. Zentralblatt fur Didaktik der Mathematik, 35(6), 282-293.

Laukkanen, R. (2008). Finnish strategy for high-level education for all. In N. C. Soguel \& P. Jaccard (Eds.), Governance and Performance of Education Systems (pp. 305-324). Dordrecht: Springer.

Laukkanen, R. (2013). Finland's experiences of compulsory education development. Artseduca, 5, 140-167.

Leung, F. (2001). In search of an East Asian identity in mathematics education. Educational Studies in Mathematics, 47 (1), 35-51.

Lewis, G. (2007). Racializing culture is ordinary. Cultural Studies, 21(6), 866-886.

Linnakylä, P. (2002). Reading in Finland. In C. Papanastasiou \& V. Froese (Eds.), Reading Literacy in 14 Countries. Lefkosia: University of Cyprus Press.

Martio, O. (2009). Long term effects in learning mathematics in Finland - curriculum changes and calculators. The Teaching of Mathematics, 12(2), 51-56.

Mason, M. (2007b). Comparing cultures. In M. Bray, B. Adamson \& M. Mason (Eds.), Comparative education research: Approaches and methods (Vol. 19, pp. 165-196). Dordrecht: Springer.

Mullis, I., Martin, M., Foy, P., \& Arora, A. (2012). TIMSS 2011 International Results in Mathematics. Boston: TIMSS \& PIRLS International Study Center, Boston College.

Mullis, I., Martin, M., Gonzalez, E., Gregory, K., Garden, R., O'Connor, K., et al. (2000). TIMSS 1999 International mathematics report. Boston: Boston College.

Niemi, H., \& Jakku-Sihvonen, R. (2006). Research-based teacher education. In R. Jakku-Sihvonen \& H. Niemi (Eds.), Research-based teacher education in Finland (pp. 31-50). Turku: Finnish Educational Research Association.

Norris, N., Asplund, R., MacDonald, B., Schostak, J., \& Zamorski, B. (1996). An independent evaluation of comprehensive curriculum reform in Finland. Helsinki: National Board of Education.

Organisation for Economic Co-operation and Development (OECD). (2001). Knowledge and skills for life: first results from the OECD programme for international student assessment (PISA) 2000. Paris: OECD.

Organisation for Economic Co-operation and Development (OECD). (2004). Learning for tomorrow's world: first results from PISA 2003. Paris: OECD.

Organisation for Economic Cooperation and Development. (2007). PISA 2006 Science competencies for tomorrow's world. Paris: OECD.

Organisation for Economic Cooperation and Development. (2010a). PISA 2009 Results: What students know and can do - Student Performance in Reading, Mathematics and Science (Vol. 1). Paris: OECD.

Organisation for Economic Cooperation and Development. (2010b). The high cost of low educational performance: The long-run economic impact of improving PISA outcomes. Paris: OECD.

Organisation for Economic Cooperation and Development. (2013). PISA 2012 results: What students know 
and can do - Student Performance in mathematics, reading and science (Vol. 1). Paris: OECD.

Oyserman, D., Coon, H., \& Kemmelmeier, M. (2002). Rethinking individualism and collectivism: Evaluation of theoretical assumptions and meta-analyses. Psychological Bulletin, 128(1), 3-72.

Osborn, M. (2004). New methodologies for comparative research? Establishing 'constants' and 'contexts' in educational experience. Oxford Review of Education, 30(2), 265-285.

Sahlberg, P. (2007). Education policies for raising student learning: the Finnish approach. Journal of Education Policy, 22(2), 147-171.

Schmidt, W., Jorde, D., Cogan, L., Barrier, E., Gonzalo, I., Moser, U., et al. (1996) Characterizing pedagogical flow: an investigation of mathematics and science teaching in six countries. Dordrecht: Kluwer.

Schwartz, S., (1999) A theory of cultural values and some implications for work. Applied Psychology, 48(1), 23-47.

Simola, H. (2005). The Finnish miracle of PISA: historical and sociological remarks on teaching and teacher education. Comparative Education, 41 (4), 455-470.

Soares, A. M., Farhangmehr, M., \& Shoham, A. (2007). Hofstede's dimensions of culture in international marketing studies. Journal of Business Research, 60(3), 277-284.

Stigler, J., and Hiebert, J. (1999) The teaching gap. New York: The Free Press.

Tarvainen, K., \& Kivelä, S. K. (2006). Severe shortcomings in Finnish mathematics skills. Matilde, 29, 10.

Triandis, H. (2001) Modern education needs cross-cultural psychology. In D. McInerney and S. van Etten (Eds.), Research on sociocultural influences on motivation and learning (Vol. 1, pp. 1-13). Greenwich CT: Information Age Publishing.

Triandis, H. (2007). Culture and psychology: A history of the study of their relationships. In S. Kitayama \& D. Cohen (Eds.), Handbook of cultural psychology (pp. 59-76). New York: Guilford Press.

Triandis, H., and Suh, E. (2002) Cultural influences on personality. Annual Review of Psychology, 53, 133160.

Tuovinen, J. (2008). Learning the craft of teaching and learning from world's best practice. The Case of Finland. In D. McInerney \& G. Liem (Eds.), Teaching and Learning: International Best Practice (pp. 5177). Charlotte: Information Age Publishing.

Tweed, R., \& Lehman, D. (2002). Learning considered within a cultural context: Confucian and Socratic approaches. American Psychologist, 57 (2), 89-99.

Välijärvi, J. (2004). The system and how does it work: Some curricular and pedagogical characteristics of the Finnish comprehensive school. Education Journal, 32(1), 31-55.

Välijärvi, J., Linnakylä, P., Kupari, P., Reinikainen, P., \& Arffman, I. (2002). The Finnish success in PISA and some reasons behind it. Jyväskylä: Institute for Educational Research, University of Jyväskylä.

Watkins, D. (2000). Learning and teaching: A cross-cultural approach. School Leadership and Management, 20 (2), 161-173.

Weber, M. (1930). The Protestant ethic and the spirit of capitalism. New York: Allen and Unwin.

Williams, R. (1958). Culture is ordinary. In N. Mackenzie (Ed.), Conviction (pp. 74-92). London: MacGibbon and Kee.

Williams, R. (1976). Keywords: A vocabulary of culture and society. London: Fontana. 